\title{
O MAGONISMO E A REVOLUÇÃO MEXICANA: UM BALANÇO POLÍTICO E IDEOLÓGICO*
}

Fabio Luis Barbosa dos Santos

Doutor em História pela Universidade de São Paulo

\begin{abstract}
Resumo
Este artigo analisa a trajetória política do magonismo - facção que encarnava a crítica radical ao porfiriato no período pré-revolucionário - a partir da eclosão da Revolução Mexicana em 1910. Ao relacionarmos sua evolução ideológica com a derrota progressiva dos revolucionários nos campos de batalha, analisamos o destino magonista sob o ângulo dos constrangimentos sofridos pela revolução-democrática nacional no México. Palavras-chave

liberalismo mexicano $\bullet$ magonismo $•$ Revolução Mexicana
\end{abstract}

Contato:

Praça Guido Cagnacci, 23

05444-060 - São Paulo - SP

E-mail: fabiobarbosasantos@gmail.com

* Apoio da Fundação de Amparo à Pesquisa do Estado de São Paulo 


\title{
MAGONISM AND THE MEXICAN REVOLUTION: A POLITICAL AND IDEOLOGICAL EVALUATION*
}

Fabio Luis Barbosa dos Santos

$\mathrm{PhD}$ in History - Universidade de São Paulo

\begin{abstract}
This article focuses the political development of magonismo - the most radical opposition to the Porfirio Díaz regime - from the onset of the Mexican Revolution in 1910. As we relate its ideological evolution to the defeats suffered by the revolutionaries in battlefield, its outcome is analysed under the light of the constraints faced by the national democratic revolution in Mexico.
\end{abstract}

Keywords

mexican liberalism • magonism • Mexican Revolution

Contact:

Praça Guido Cagnacci, 23

05444-060 - São Paulo - SP

E-mail: fabiobarbosasantos@gmail.com

* Scholarship-holder of Fundação de Amparo à Pesquisa do Estado de São Paulo 


\section{Introdução}

Este artigo realiza um balanço político e ideológico do magonismo, facção mais radical dos liberais mexicanos que se organizaram nos primeiros anos do século XX para combater a ditadura de Porfirio Díaz no México, no poder desde 1876. A questão subjacente é compreender por que a organização política que encarnava a oposição radical à ditadura foi incapaz de assumir a direção do processo quando a revolução que fomentou durante anos finalmente eclodiu.

A reivindicação posterior de Ricardo Flores Magón (1874-1922) pelo movimento anarquista convidou a leituras simplistas da sua trajetória, ${ }^{1}$ ignorando sua fidelidade absoluta ao programa do Partido Liberal, de 1906 até sofrer derrotas decisivas nos campos da batalha revolucionária. ${ }^{2}$ Este programa propõe um projeto de democratização radical da sociedade mexicana nos marcos do capitalismo e será apontado por muitos autores como um dos antecedentes emblemáticos da constituição mexicana de $1917 .{ }^{3}$ A despeito da radicalização ideológica de muitos

\footnotetext{
${ }^{1}$ A reivindicação seminal é: SANTILLAN, Diego Abad de. Ricardo Flores Magón. El Apóstol de la Revolución Social Mexicana. Cidade do México: CEHSMO, 1978. Também: TURNER, Ethel Duffy. Ricardo Flores Magón y el Partido Liberal Mexicano. Cidade do México: Comisión Editorial Nacional, 1984. Esta abordagem redutora predomina nos trabalhos que abordam Flores Magón e também nas análises da revolução mexicana que o mencionam. Por exemplo: BLANQUEL, Eduardo. Ricardo Flores Magón. Cidade do México: Editorial Terra Nova, 1985. CÓRDOVA, Arnaldo. La ideología de la Revolución Mexicana. La formación del nuevo regimen. $23^{a}$ reimpressão. Cidade do México: Era, 1973. Exceções recentes são: no primeiro caso, TORRES PARÉS, Javier. La Revolución sin frontera. Cidade do México: UNAM, 1990. No segundo: KATZ, Friederich. The life and times of Pancho Villa. Palo Alto: Stanford University Press, 1998. Como o nosso objetivo é explicitar a insuficiência do rótulo anarquista para explicar a trajetória de Flores Magón, nosso foco não será as influências libertárias que sofreu, tratadas pela bibibliografia mencionada.

2 Outro equívoco dominante é interpretar Flores Magón e o PLM como precursores da revolução mexicana, abordagem que desconsidera a derrota militar e política sofrida na revolução. $\mathrm{O}$ trabalho fundamental nesta linha é o livro precursor de COCKROFT, James D. Precursores intelectuales de la Revolución Mexicana (1900-1913). Traducción de María Eunice Barrales. Cidade do México: Siglo XXI, 1985. A tese de Blanquel, republicada recentemente em livro, revela esta leitura em seu título: El pensamiento político de Ricardo Flores Magón, precursor de la Revolución Mexicana. Em: BLANQUEL, Eduardo. Ricardo Flores Magón y la Revolución Mexicana y otros ensayos históricos. Prólogo, selección y edición Josefina Mac Gregor. Cidade do México: Colegio de México, 2008. Os ensaios de Armando Bartra contestam esta visão: BARTRA, Armando. La revolución mexicana en la perspectiva del magonismo. In: GILLY, Adolfo (Org.). Interpretaciones de la Revolución Mexicana. Cidade do México: UNAM, Editorial Nueva Imagen, 1980. Também sua introdução a: Regeneración (1900-1918). La corriente más radical de la revolución mexicana a través de su periódico de combate. Cidade do México: Era, 1977.

3 DÍAZ, Lilia (selección y traducción). Planes políticos y otros documentos. Fuentes para la historia de la Revolución Mexicana. Prólogo de Manuel González Ramirez. Cidade do México: FCE, 1954. Sobre a relação com a constituição de 1917: SILVA HERZOG, Jesus. Breve Historia de la Revolución Mexicana. 2 tomos. 15ª reimpressión. Cidade do México: FCE, 1995.
} 
membros da Junta Liberal no exílio, a percepção que tinham do modesto acúmulo político da classe trabalhadora mexicana determinou a subordinação das suas convicções pessoais ao cálculo das potencialidades políticas franqueadas pela conjuntura, proporcionando o cultivo de possibilidades várias, desde a aliança com os setores anti-porfiristas das classes dominantes até a ruptura irreversível nos campos de batalha. ${ }^{4}$

Este percurso é evidenciado por meio do cotejo do movimento ideológico do partido com os acontecimentos chaves que determinaram a sua derrota no início da revolução. Tal cotejo foi viabilizado pela recente publicação dos primeiros tomos das obras completas de Ricardo Flores Magón e pela disponibilização da coleção completa dos exemplares do periódico Regeneración, em CD-ROM, principal veículo da articulação política liberal. ${ }^{5}$ Esse exercício comparativo revela que o fracasso magonista não deve ser debitado ao anarquismo, mas está referido à intransigência dos setores anti-porfiristas das classes dominantes, que se negavam a incorporar as demandas sociais da revolução e atuavam com determinação inflexível para conter as pressões democratizadoras do processo. Em suma, este trabalho propõe um reenquadramento da análise do magonismo sob o ângulo dos constrangimentos que a revolução democrática-nacional encontrou para afirmar-se como via histórica para o capitalismo mexicano.

É somente no contexto da derrota das forças liberais no campo de batalha, coetânea ao avanço da rebelião camponesa, que Ricardo Flores Magón reorienta as consignas liberais em um sentido anticapitalista. Em outras palavras, é diante da incapacidade da classe dominante dividida de integrar as demandas sociais como caminho para a paz nacional que os liberais radicalizam suas bandeiras. $\mathrm{Na}$ medida em que é desencadeada pela derrota militar, a radicalização ideológica corresponde a uma progressiva impotência política dos magonistas. Em contradição com a racionalidade política prevalente no período pré-revolucionário,

\footnotetext{
${ }^{4}$ O refinamento da visão política de Ricardo Flores Magón escapa aos trabalhos recentes de mexicanistas a que tivemos acesso. WARD, Albro S. Always a rebel. Ricardo Flores Magón and the Mexican Revolution. Fort Worth: Texas Christian University Press, 1992. MACLACHLAN, Colin. Anarchism and the Mexican Revolution - the political trials of Ricardo Flores Magón in the United States. Berkeley: University of California Press, 1991. RAAT, Dirk W. Los revoltosos. Rebeldes mexicanos en los Estados Unidos (1903-1923). México: FCE, 1993. BLAISDELL, Lowell L. La revolución del desierto. Baja California, 1911. México: SEP, 1993.

5 FLORES MAGÓN, Ricardo. Obras Completas - Vol. I - Correspondencia (1898-1918). Vol. II - Correspondencia 2 (1919-1922). Vol. III - Regeneración (1900-1901) primera parte. Vol. IV - Regeneración (1900-1901) segunda parte. Vol. V - Artículos Políticos Seudónimos. Introducción, compilación y notas, Jacinto Barrera Bassols. Cidade do México: Conaculta, 2001. Também: Regeneración. Edição completa em CD-Rom. BASRRERA BASSOLS, Jacinto (org.).
} 
Flores Magón aposta no instinto das massas, enaltece a iniciativa popular espontânea e, ao mesmo tempo, enfatiza os vínculos entre o processo mexicano e a inexorabilidade da revolução mundial, apelando a um sentido teleológico da história ausente até então. Em síntese, o líder mexicano opera uma aproximação entre natureza e história que resulta em um esvaziamento da política, o que termina por reforçar as debilidades do campo popular da revolução com o qual se identifica e é derrotado.

Inicialmente, o artigo situa a formação e atuação da Junta Liberal no exílio no período da ditadura encabeçada por Porfirio Díaz. Em seguida, acompanhamos a fortuna política dos magonistas ao longo da revolução, concedendo especial importância ao processo que conduz à ruptura com os maderistas, fator decisivo para a radicalização das consignas liberais explicitada no manifesto de setembro de 1911. Por fim, esboçamos um balanço político e ideológico do conjunto da trajetória magonista.

\section{Magonismo e Porfiriato}

A conjunção entre a expansão da demanda mundial por produtos primários e o imperativo da estabilidade institucional como premissa para o investimento capitalista está na raiz da longa supremacia política de Porfirio Díaz (1876-1911), a qual projetou o México em um período de acelerado crescimento econômico, que se estenderia até a revolução. A consolidação do Estado mexicano esteve associada ao papel que assumiu como mediador entre os negócios do capital internacional e os requisitos sociais e políticos necessários para a sua penetração, estabelecendo uma realidade na qual o investimento internacional e a Pax Porfiriana se retroalimentavam. ${ }^{6}$

Embora no plano econômico verifique-se uma continuidade entre o desígnio da reforma e a modernização realizada pelo Porfiriato, a chamada "pacificação" que lhe serviu de alicerce assentou-se na mutilação da dimensão social e política do programa liberal. Em um regime onde a modernização do país foi afirmada

\footnotetext{
${ }^{6}$ Nos baseamos em: KATZ, Friederich. The liberal republic and the Porfiriato. 1876-1910. In: BETHELL, Leslie (Ed.). Mexico since independence. Cambridge: Cambridge University Press, 1991. KATZ, Friederich (compilador). Revuelta, rebelión y revolución. La lucha rural en México del siglo XVI al siglo XX. 2 tomos. Cidade do México: Era, 1990. CARR, Barry. El movimiento obrero y la politica en México. 1910/1929. Cidade do México: Era, 1981. COSÍO VILLEGAS, Daniel (Cood.). Historia General de México. 2 tomos. Cidade do México: El Colegio de Mexico, 1976. COSÍO VILLEGAS, Daniel (Coord.) Historia Moderna de México. El Porfiriato, vida economica. 2 tomos. Cidade do México: Hermes, 1965.
} 
como razão de Estado, o imperativo da ordem justificou a determinação em silenciar qualquer foco de distúrbio social, seja de caráter caudilhesco, étnico ou de classe. Assim, o desenvolvimento econômico superficial dissimulava o acirramento das contradições sociais que a sua rigidez política encetava e que terminaria explodindo de forma espetacular.

A crônica convencional do desabamento do Porfiriato se inicia nos primeiros anos do século XX, tendo como ponto de partida a reunião convocada pelo Círculo Liberal Ponciano Arriaga na cidade de San Luis Potosí, em 1901, quando se aglutinaram entidades politicamente afins de diversas partes do país. Este encontro serviu de impulso original para a articulação do Partido Liberal Mexicano, que em pouco tempo seria liderado por Ricardo Flores Magón, na época coeditor do recém-fundado periódico Regeneración (1900-1918).

Inicialmente inspirado pelas divisas anticlericais e legalistas herdadas da Reforma liberal de meados do século XIX, os liberais mexicanos radicalizaram progressivamente suas posições diante da perseguição implacável da ditadura. Depois de sofrer seguidas vezes com a prisão e o fechamento do jornal, Flores Magón teve proibida pelo governo a publicação de qualquer escrito seu. Nesta circunstância refugiou-se nos Estados Unidos (1904), de onde assumiu a liderança da Junta Liberal no exílio. Convencido de que estavam fechadas as vias para a mudança social dentro da ordem, o Partido conspirou incansavelmente para derrubar a ditadura pela via revolucionária, envolvendo-se com as principais agitações operárias da época e iniciando, por duas vezes, um levante armado no norte do país, de modo a consolidar uma reputação de oposição radical ao Porfiriato no período pré-revolucionário.

Neste contexto, com o objetivo de prover a conspiração anti-porfirista de um horizonte ideológico, perfilou-se nos escritos de Ricardo Flores Magón o que podemos qualificar como um pensamento distintivamente magonista ${ }^{7}$. Ao distanciar-se do legalismo que marca a reivindicação do liberalismo mexicano do século XIX, Flores Magón produzirá, à frente da Junta Liberal, um discurso caracterizado pela progressiva incorporação da temática social e pelo seu correspondente direcionamento aos trabalhadores. Não obstante a sua progressiva radicalização, nossa hipótese é que Magón preservará uma coerência fundamental, lastreada na herança ideológica do liberalismo mexicano e conjugada a uma

\footnotetext{
Embora Ricardo Flores Magón e seus partidários se identifiquem como liberais, portanto, genuínos seguidores da tradição juarista, e não como "magonistas," o termo delimita com maior precisão a especificidade das ideias veiculadas pelo partido e seu líder a partir de então.
} 
visão de mundo de inspiração positivista. Essa coerência centra-se no tema da liberdade, que articulará uma convergência fundamental entre natureza humana e história, cujas decorrências políticas se explicitarão no processo revolucionário.

O eixo principal da sua radicalização será a evolução da própria noção de liberdade: entendida como mera liberdade política nos anos iniciais do periódico Regeneración, a incorporação da temática social dilata progressivamente o seu conteúdo, desaguando na noção de liberdade econômica. Inicialmente vinculada aos objetivos políticos liberais de maneira associada e subalterna, as consignas relacionadas às relações de produção gradualmente se diferenciam até se afirmarem como o foco do projeto magonista na sua última fase. Os documentos que balizam esta evolução são o célebre programa promulgado pela Junta Organizadora do Partido Liberal no exílio em 1906 e o manifesto difundido em setembro de 1911, quase um ano após a eclosão da revolução, quando o foco da denúncia magonista se deslocará para a superação da propriedade privada.

O programa promulgado pela Junta Liberal em $1^{\circ}$ de julho de 1906 é um documento célebre na análise posterior da Revolução Mexicana, considerado por muitos autores como o antecedente ideológico por excelência da constituição de 1917. Embora provavelmente não tenha sido redigido apenas por Flores Magón, servirá como referência precípua de toda ação subsequente do partido até a revolução.

Uma costura dos temas clássicos do liberalismo mexicano, como liberdades civis e anticlericalismo, com uma detalhada agenda de reformas sociais que objetiva integrar os trabalhadores urbanos e rurais, é apresentada no programa. Com este objetivo, avança uma série de propostas destinadas a melhorar as condições de trabalho na indústria e um projeto de reforma agrária centrado na desapropriação do latifúndio improdutivo. Contempla ainda propostas de cunho nacionalista (como limitações à propriedade e ao emprego de estrangeiros), uma reforma tributária, a proteção da raza indígena e o estabelecimento de lazos de unión con los países latinoamericanos. Em suma, é um projeto nacional orientado ao estabelecimento do capitalismo autodeterminado por meio da integração da população através do trabalho. ${ }^{8}$

\footnotetext{
8 Na sua exposição, lê-se: "Cuando los millones de parias que hoy vegetan en el hambre y la desnudez coman menos mal, usen ropa y calzado y dejen de tener petate todo por ajuar, la demanda de mil géneros y objetos que hoy es insignificante aumentará en proporciones colosales, y la industria, la agricultura, el comercio, todo será materialmente empujado a desarrollarse en una escala que jamás alcanzaría mientras subsistieran las actuales condiciones de miseria general". Plan del Partido Liberal. In: DÍAZ. Lilia (selección y traducción).Planes políticos y otros do-
} 
Embora a convicção de membros da junta no exílio evolua para posições anticapitalistas, a fidelidade política ao programa liberal está assentada em um diagnóstico onde o ceticismo em relação ao espaço para a reforma no regime porfirista é contrabalançado por uma percepção modesta das possibilidades de ação política dos trabalhadores mexicanos. A exitosa combinação de cooptação e repressão, realizada pelo porfiriato em um contexto de acelerado crescimento econômico, convergiu para minimizar os nexos de continuidade entre as lutas trabalhistas desencadeadas no contexto da Reforma, ainda fortemente marcadas pela tradição mutualista, e o desabrochar das lutas operárias segundo um padrão moderno no século XX, condenando os trabalhadores mexicanos a um incipiente acúmulo político e ideológico. ${ }^{9}$ Nessa circunstância, o objetivo de classe assumido pela Junta Liberal é superar o paternalismo como padrão dominante nas relações de trabalho mexicanas, seja no campo, de onde provem a maior parte do contingente operário, seja na cidade, onde persiste o legado mutualista. Objetivo, cujo fim é elevar o potencial de reivindicação da classe trabalhadora aos patamares mínimos de organicidade e combatividade necessários para a conquista de direitos elementares. Nessa perspectiva, o horizonte imediato da luta de classes no México configura-se como a superação do legado porfirista, tendo como referência política o capitalismo autodeterminado:

Es preciso que dejen de creer que su situación miserable se debe a la fatalidad y que si sufren se debe a que no les tocó en suerte nacer en telas de seda. El que trabaja tiene derecho a que le pague bien, a que no se le robe en las tiendas de raya, a ocupar un lugar decente en la sociedad. Nuestros obreros deben tomar ejemplo de los obreros yanquis que han sabido hacerse respetar, por lo que gozan un bienestar con que aquí no se sueña. ${ }^{10}$

Ao propor uma atualização do pensamento radical mexicano através da dilatação da agenda liberal, avançando a centralidade da questão do trabalho como via de superação do atraso mexicano, Flores Magón pretende sintonizar

cumentos. Fuentes para la historia de la Revolución Mexicana. Prólogo de Manuel González Ramirez. Cidade do México: FCE, 1954.

9 Ver: CARR, Barry. El movimiento obrero y la política en México, 1910-1929. Cidade do México: Era, 1981. CANTÚ, Gastón García. El socialismo en México - siglo XIX. Cidade do México: Era, 1986. HART, Jonh. Anarchism and the Mexican working class (1860-1931). Austin: University of Texas press, 1971. Este autor usa critérios problemáticos para reconstruir uma tradição anarquista mexicana, reivindicando para isso autores que na obra percursora de Gastón Garcia Cantú aparecem referidos ao socialismo e que por vezes se identificam como tal.

10 Artigo em: El Colmillo Público, 11/03/1906. In: FLORES MAGÓN, Ricardo. Obras completas Volumen V. Artículos Políticos Seudónimos. BARRERA BASSOLS, Jacinto (Introducción, compilación y notas). Cidade do México: Conaculta, 2001, p. 254. 
os problemas nacionais com o sentido da história universal contemporânea, que aponta para a concretização do preceito intelectualmente aceito da igualdade entre os homens. Nessa perspectiva, o diagnóstico revolucionário e o programa da Junta Liberal situam-se na interligação entre as possibilidades e os limites da conjuntura mexicana e as grandes questões do tempo: considerando a ausência de espaço para a reforma dentro da ordem, é necessário realizar uma revolução mexicana que promova a integração da classe trabalhadora, a fim de gerar as condições para o seu progressivo protagonismo em sintonia com o movimento geral da história universal.

Consciente das limitações da classe trabalhadora mexicana, a Junta liderada por Flores Magón persistirá fiel ao programa democrático nacional do partido, subordinando conviç̧ões pessoais e rótulos ideológicos aos desígnios da luta política até a frustração da aliança com setores anti-porfiristas das elites nos campos da batalha revolucionária. ${ }^{11}$ É somente quando a marcha da revolução evidencia a intransigência social dos maderistas, ao mesmo tempo que revela a irresistível radicalização da luta popular no campo, que os liberais serão constrangidos a reavaliar as possibilidades políticas do momento histórico, a elas ajustando o seu programa.

\section{Magonismo e a revolução mexicana}

Como se sabe, em um primeiro momento, a convocação ao levante armado realizada por Madero, a partir dos Estados Unidos, provocou uma resposta irregular e pouco promissora em território mexicano. Do lado dos magonistas, decididos a aproveitar a agitação e somar forças ao levante sem abrir mão da sua autonomia, a Junta reconhece que os núcleos ainda não estavam prontos para tomar as armas, embora incentive os preparativos para esta finalidade. ${ }^{12}$

A explosão do confronto em Chihuahua no fim de 1910, que rapidamente transbordou o controle da junta maderista, estimulou outros levantes que logo

\footnotetext{
${ }^{11}$ Mesmo posteriormente quando a revolução se radicaliza e a Junta reorienta suas consignas na direção da expropriação da propriedade privada, a definição ideológica aparece subordinada ao conteúdo da luta: "Es por el llamado pueblo bajo por el que lucho. Que esto sea socialismo, que esto sea anarquismo, no me importan las denominaciones". FLORES MAGÓN, Ricardo. Carta a Luis Rivas Iruz (3/6/1911). In: Obras Completas - Vol. I. Correspondencia (1898-1918). BARRERA BASSOLS, Jacinto (Introducción, compilación y notas). Cidade do México: Conaculta, 2001, p. 592.

12 Nas vésperas do ano novo, Regeneración publica: "La Junta trabaja con toda actividad por completar la organización de los grupos que han de rebelarse en México en un momento dado". Regeneración, número 17, 24/12/1910. Edição digital completa.
} 
incendiariam o país. ${ }^{13}$ Diversos grupos liberais se alçaram em armas nesta região, mas sofreram uma perda importante quando seu principal dirigente, Práxedis Guerrero, perdeu a vida, na tomada do povoado de Janos em 30 de dezembro. Impelida pelas circunstâncias, a Junta publicou na semana seguinte suas Instrucciones Generales a los Revolucionarios, exortando os grupos liberais ainda não sublevados a aderir imediatamente à luta.

Nesse cenário, Madero relutou em atravessar a fronteira mexicana, e encarar o confronto em uma região que não era reduto seu, para liderar politicamente uma guerra que não comandava: Pascual Orozco e Pancho Villa emergiam como lideranças indiscutíveis, mas de subordinação duvidosa. Empurrado por uma ordem de prisão emitida nos Estados Unidos, Madero retornou ao México em fevereiro de 1911 e precisou usar de toda habilidade para costurar sua liderança sobre os grupos rebelados. Esta manobra teve como premissa a cooptação ou o desbaratamento dos grupos levantados sob a bandeira liberal. O primeiro a ser preso foi Prisciliano Silva, líder de um núcleo rebelde no povoado tomado de Guadalupe, para onde já se dirigira Madero. Silva recusou-se a reconhecer o mando maderista, ainda que antes tivesse atendido a um apelo de cooperação militar. Como resposta, em 25 de fevereiro de 1911, o Regeneración denuncia Madero como traidor, fechando as possibilidades de colaboração na luta. ${ }^{14}$

Para prosseguir na delicada tarefa de neutralização dos liberais, Madero se viu impossibilitado de recorrer a Orozco, principal liderança militar então, mas que tinha vínculos pregressos com os magonistas e já se recusara a desarmá-los. O cumprimento dessa missão selaria a fidelidade de Villa, que até então não tinha atuação política, com Madero. Em contrapartida, despertou-se o ódio dos liberais pelo caudilho de Durango, o que teve consequências dramáticas para o alinhamento

\footnotetext{
${ }^{13} \mathrm{Na}$ bibliografia da crônica dos eventos, o enorme livro de Alan Knight faz um esforço de amealhar a miríade de episódios e motivações regionais, étnicas e de classe que compuseram o processo revolucionário em um país escassamente integrado e dá uma boa ideia da sua complexidade, embora de outro lado careça de um referencial interpretativo capaz de conferir sentido ao conjunto impressionante de informações que reúne. KNIGHT, Alan. The Mexican Revolution. 2 tomos. Lincoln: University of Nebraska Press, 1990. Para uma síntese dos debates sobre o caráter da revolução, ver do mesmo autor: Interpretaciones recientes de la Revolución Mexicana. Revista Secuencia, Cidade do México: Instituto de Investigaciones Dr. José María Luis Mora, núm. 13, ene.-abr., 1989, p. 23-43.

${ }^{14}$ Como decorrência, o texto das instrucciones generales a los revolucionarios é alterado. No ponto 11, onde se lia: "La causa del Partido Liberal es distinta de la causa maderista, por ser la liberal la causa de los pobres; pero en caso dado, ya sea para la resistencia como para el ataque, pueden combinarse ambas fuerzas y permanecer combinadas por todo el tiempo que dure tal necesidad". Agora se escreve: "En ningún caso deberán combinarse las fuerzas liberales con las fuerzas maderistas".
} 
de forças no futuro do processo: somente em 1916, passado o ápice do impulso revolucionário, os magonistas deixariam de tratar Villa como um bandido. ${ }^{15}$

A ruptura da possibilidade de aliança supra-classista com o setor anti-porfirista das elites representado pelo maderismo, aliada à generalização do enfrentamento no campo protagonizado pela miríade de forças populares, resultou em uma guinada ideológica nas páginas de Regeneración: a denúncia social é dirigida cada vez mais diretamente contra a propriedade privada e o capitalismo ${ }^{16}$, respondendo, de um lado, a uma aceleração do processo revolucionário e, de outro, ao desígnio de diferenciação em relação ao maderismo, cujo prestígio cresce a despeito dos seus propósitos sociais acanhados. Constrangido a se posicionar em relação às negociações de Madero com Díaz, Flores Magón expressa pela primeira vez com clareza o desígnio de expropriação imediata das forças produtivas - e não só da terra: "La Junta contestó que no ha tomado parte en ésas negociaciones ni está por la paz, á menos que se acepten todas las demandas del Partido Liberal Mexicano comenzando por la expropiación de la tierra y de los útiles de trabajo para que tome posesión de todo ello el pueblo (...)". ${ }^{17}$

A trajetória de Madero chega a seu ápice em maio de 1911, quando as forças combinadas de Villa e Orozco tomam Ciudad Juárez a despeito de ordens contrárias do seu líder político, precipitando a queda de Porfirio Díaz e a assinatura do tratado de paz nesta cidade. O ditador deixa o país rumo ao exílio francês, e no começo de junho Madero entra triunfante na Cidade do México. O partido Antireeleccionista convoca eleições para outubro, entende que a revolução está encerrada e assume a tarefa de concluir a pacificação do país: "Madero had considered Porfirio Díaz as his primary enemy, and once Díaz was gone, he felt he could now turn his energies toward combating the radical revolutionaries". ${ }^{18}$

\footnotetext{
${ }^{15}$ Sobre as relações entre Madero, Villa e os liberais ver: KATZ, Friederich. The life and times of Pancho Villa. Palo Alto: Stanford University Press, California, 1998.

${ }^{16}$ Uma busca por palavras na versão digitalizada de Regeneración confirma esta afirmação: a consigna Tierra y Libertad se generaliza a partir de março de 1911, número 26; o termo expropiación, a partir do número 29; propriedad individual observa-se a partir do número 33, de abril; proletário, embora ocorra anteriormente, se afirma como tratamento vocativo; propiedad privada se generaliza a partir do número 50, agosto 1911, conjuntamente com comunismo; capitalismo recorre a partir do número 20. Regeneración. Edição digital completa em CD Rom.

${ }^{17}$ Artigo: NO QUEREMOS UNA PAZ INFAME. "La Prensa Unida preguntó - hoy (31 de Marzo) a la Junta Organizadora del Partido Liberal Mexicano si habia tomado parte en las conferencias de paz celebradas entre representantes de Porfirio Díaz y de Francisco I. Madero". E segue a citação acima. Regeneración (1/4/1911). Em: edição digital completa em CD Rom.

18 KATZ, Friederich. The life and times of Pancho Villa. Palo Alto: Stanford University Press, 1998, p. 130.
} 
Embora as forças identificadas com os liberais não fossem o contingente radical mais beligerante em uma circunstância onde os zapatistas, por exemplo, já estavam rebelados em Morelos, o novo presidente não poupou esforços para submetê-los, recorrendo à cooptação ou ao esmagamento. Menos de uma semana depois da entrada triunfal de Madero na capital, a Junta Liberal recebeu na Califórnia a visita de Juan Sarabia, mártir liberal recém-egresso do infame presídio de San Juan de Ulúa, e Jesus Flores Magón, irmão mais velho do líder liberal. Sua missão, que não teve sucesso, era conseguir a adesão dos magonistas ao novo regime. A intransigência da Junta foi premiada com a prisão de seus líderes, Flores Magón inclusive, pela polícia dos Estados Unidos no dia seguinte, sob a acusação de infringir as leis de neutralidade.

Um mês depois, o conjunto de liberais que romperam com a Junta no exílio e optaram pelo apoio crítico a Madero organizaram a dissidência através da Junta Iniciadora de la Reorganización del Partido Liberal na Cidade do México, dando início à publicação de um periódico de vida curta, também chamado Regeneración. ${ }^{19}$ Esse movimento corresponde à ruptura dos socialistas dos Estados Unidos com os magonistas pelo mesmo motivo, inaugurando uma polêmica acerca do caráter da Revolução Mexicana.

Onde a cooptação foi insuficiente para submeter os focos de rebeldia, Madero não vacilou em empregar o exército federal na sua repressão. Do lado magonista, embora em muitos casos seja difícil precisar a filiação partidária dos bandos levantados, é plausível que durante 1911 houvesse grupos identificados com o liberalismo em armas em todo o país.

No entanto, a ação mais espetacular impulsionada pela Junta acontecia no remoto território de Baja California, na fronteira com os Estados Unidos na costa oeste. Ali, uma força estimada em 220 homens, liderada por mexicanos e integrada por radicais e simpatizantes de múltiplas nacionalidades, muitos deles filiados à IWW (Industrial Workers of the World), lançou um assalto no final de janeiro de 1911 e tomou a cidade de Mexicali. Em fevereiro seria tomada Algodones,

\footnotetext{
19 Muitos quadros liberais dissidentes desenvolverão uma intensa atividade política nos anos seguintes, principalmente no interior do movimento operário mexicano, que transcenderá o período revolucionário. Alguns se juntarão ao zapatismo enquanto outros seguirão carreira política, participando da Assembleia Constituinte em 1917 e/ou assumindo cargos públicos nos governos sucessivos. Um grupo de dissidentes se aproximou do pequeno recém-formado Partido Socialista, desenvolvendo atividades significativas no movimento operário mexicano e participando da fundação da Casa del Obrero Mundial. Parte do PS desaguaria na fundação do Partido Comunista Mexicano em 1919. Ver: TORRES PARÉS, Javier. La revolución sin fronteras. Cidade do México: UNAM, 1990, p. 139-142.
} 
em março Tecate e em maio, nos mesmos dias do assalto a Ciudad Juarez em Chihuahua, Tijuana. Ao que tudo indica, a intenção dos liberais era estabelecer uma espécie de território livre que pudesse servir de base e retaguarda para a expansão do movimento armado.

Mas o projeto não vai adiante: abalado por dissidências internas, deserções para o maderismo e uma campanha difamatória bi-nacional que acusa propósitos filibusteiros à iniciativa, a região é gradualmente recuperada a partir de 22 de junho quando as forças federais, respondendo agora a Francisco Madero, retomam Tijuana com o apoio explícito do governo dos Estados Unidos, que permite o deslocamento de tropas através do seu território. ${ }^{20}$

Simultaneamente à derrota militar, a esperança dos magonistas se deslocou para o movimento operário, que, dando vazão às represadas reivindicações dos trabalhadores urbanos, estava em vigoroso ascenso em todo o país desde a queda da ditadura. ${ }^{21}$ Os magonistas estimulam entusiasticamente as greves, insistindo na necessidade de transcender a sua modalidade pacífica, limitada a frear a produção, e partir para a expropriação dos meios de produção com o objetivo de consolidar a liberdade econômica. O caráter econômico da revolução em curso é defendido na manchete da edição de 8 de julho:"La Revolución economica en México - la huelga general en casi todo el país".22

Ao apontar para a dimensão econômica da revolução, os magonistas enfatizam a tendência ao enfrentamento direto e imediato do capitalismo. Com isso, o alcance do processo mexicano transcenderia as fronteiras nacionais, assumindo a vanguarda mundial no enfrentamento deste sistema. A causa mexicana pertence então à classe trabalhadora mundial. Nessa circunstância, Flores Magón intensifica a mobilização da solidariedade internacional de classe e é levado a

\footnotetext{
${ }^{20}$ Neste mesmo período, os maderistas acordam uma trégua com os zapatistas em Morelos, rompida em agosto quando o general Huerta ataca e aniquila as forças desarmadas de Zapata. Como se sabe, esse exército federal não foi desmontado por Madero e dará o golpe liderado pelo próprio Huerta, que culminará no assassinato de Madero em fevereiro de 1913. A rede de espionagem internacional montada por Creel também foi utilizada por Madero. Ver: RAAT, Dirk. Los revoltosos. Rebeldes mexicanos en los Estados Unidos (1903-1923). Cidade do México: FCE, 1993.

21 "Al propagarse por la República la noticia de la rebelión maderista, se formó de modo inmediato una gran variedad de sindicatos y agrupaciones obreras cuya ideología iba desde el mutualismo tradicional hasta el anarcosindicalismo". CARR, Barry. El movimiento obrero y la política en México. 1910/1929. Cidade do México: Era, 1981, p. 45. "En junio de 1911 se inició una ola de huelgas que barrió todo el país, exigiéndose grandes aumentos de salarios, la reducción de la jornada de trabajo y la abolición de algunas prácticas administrativas hostiles a los obreros". Idem, Ibidem.

${ }^{22}$ Regeneración, n. 45 (8/7/1911). Edição digital completa.
} 
desafiar teoricamente a leitura dos socialistas dos Estados Unidos, os quais, em sintonia com os liberais dissidentes que apoiam o maderismo, entendem que a Revolução Mexicana está encerrada. Nessa tarefa, Flores Magón precisa enfrentar o etnocentrismo do movimento operário internacional e provar que o povo mexicano rebelado, apesar do atraso civilizatório a que a ditadura o confinou, está em condições de proceder à luta anticapitalista. Em outras palavras, precisa enfrentar o desafio teórico de fundamentar a revolução em um país agrário, tornando positiva a especificidade mexicana.

Esta tarefa é realizada através de um duplo movimento. De um lado, Magón reafirma a natureza anti-autoritária dos homens em geral e dos mexicanos em particular, dadas as circunstâncias repressoras em que vivem. Consequência desta aproximação entre rebeldia e natureza humana é a afirmação da primazia da ação sobre a liderança e a ilustração:

Para la toma de posesión de la tierra y de los instrumentos de trabajo en México no se ha necesitado de "leaders", de "amigos" de la clase trabajadora, ni han hecho falta - "decretos paternales","leyes sabias" ni nada de eso. La acción lo ha hecho y lo está haciendo todo. ${ }^{23}$

Este movimento contradiz a visão liberal prevalente nos anos pré-revolucionários, segundo a qual o partido deveria cumprir um papel fundamental para canalizar as energias rebeldes latentes. ${ }^{24}$

De outro lado, Magón procede a uma valorização do legado indígena para a formação mexicana: ao identificar uma prática comunista nas formas pré-colombianas de organização da produção no campo mexicano, ele recusa a associação de índios e camponeses com o atraso, apontando um potencial progressista nos modos de vida ancestrais. Por trás desta reivindicação política está um movimento ideológico de aproximação entre a natureza humana e o comunismo. Diante destes argumentos, a conclusão se impõe: "Se ve, pues, que el pueblo mexicano

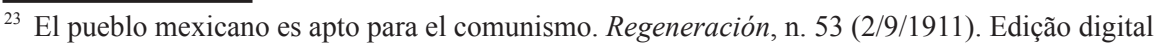
completa em CD Rom.

24 "Pero si este movimiento espontáneo, producido por el instinto de la propia conservación, es inconsciente para la masa obrera mexicana, en general no lo es para una minoría selecta de la clase trabajadora de nuestro país, verdadero núcleo del gran organismo que resolverá el problema social en un porvenir cercano". En pos de la libertad. Regeneración, novembro de 1910. In: BARTRA, Armando (Prólogo, seleción y notas). Regeneración, 1900-1918. La corriente más radical de la revolución mexicana de 1910 a 1918 através de su periódico de combate. Cidade do México: Era, 1977, p. 246.
} 
es apto para llegar al comunismo, porque lo ha practicado, al menos em parte, desde hace siglos". ${ }^{25}$

Esta posição se cristaliza no manifesto publicado pela Junta Liberal em 23 de setembro de 1911, o qual procura superar o programa de 1906, propondo o enfrentamento imediato da propriedade privada.

La Junta Organizadora del Partido Liberal mexicano ve con simpatia vuestros esfuerzos para poner em práctica los altos ideales de emancipcaión política, econômica y social, cuyo império sobre la tierra ponderá fin a esa ua bastante larga contienda del hombre contra el hombre, que tiene su origen en la desigualdad de fortunas que nace del principio de la propiedad privada. ${ }^{26}$

A radicalização programática da Junta corresponde à progressiva frustração da liderança militar liberal. Diante da impotência para conduzir o movimento no seu primeiro ano, confrontada com a ascensão de Madero, a generalização da guerra camponesa e as hesitações e contradições do movimento urbano, a Junta não revigora esforços no sentido de constituir uma direção política nacional alternativa ao maderismo e seus congêneres. Em vez disso, centra progressivamente suas esperanças na realização instintiva das aspirações anticapitalistas dos trabalhadores: "El pueblo mexicano odia, por instinto a la Autoridad y a la burguesía". ${ }^{27}$ Nessa perspectiva, o êxito da luta depende não de uma direção eficaz, mas da emancipação de individualidades oprimidas. É o indivíduo consciente, e não o partido, que se opõe à massa passiva, dependente da ação de um chefe: "No hay que ser masa: hay que ser conjunto de individualidades pensantes". ${ }^{28}$

Assim como a rebeldia é individualizada, a implementação da sociedade sem autoridade é fragmentada, delegada à miríade de focos de insubordinação espalhados pelo país, que procedem de forma imediata à sua realização. Como consequência, estão ausentes os problemas da centralização do poder revolucionário, do Estado e da transição à sociedade sem classes.

É nesta perspectiva que se entende a relutância de Flores Magón em transladar-se para território revolucionário. Vista do ângulo da inexorabilidade da revolução, certamente favorecido pela sequência dos eventos onde sucessivos

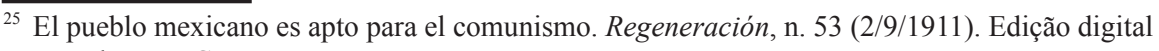
completa em CD Rom.

${ }^{26}$ Manifiesto del 23 de septiembre de 1911. Regeneración. Edição digital completa em CD Rom.

${ }^{27}$ FLORES MAGÓN, Ricardo. Obras Completas - Vol. I. Correspondencia (1898-1918). BARRERA BASSOLS, Jacinto (Introducción, compilación y notas). Cidade do México: Conaculta, 2001, p. 636

${ }^{28}$ Los Jefes. Regeneración (15/6/1912). Edição digital completa em CD Rom.
} 
governos tombaram, Flores Magón enxerga no processo mexicano um capítulo extraordinário do enfrentamento mundial entre o trabalho e o capital, atribuindo papel fundamental à solidariedade internacional das classes trabalhadoras, a qual tem como papel precípuo frear o intervencionismo dos Estados Unidos, principal ameaça ao fluxo espontâneo da insurreição. Avalia que o melhor serviço que pode prestar à causa não é a sua condução, que de todo modo não é factível postular, mas auxiliar na proteção necessária para que os acontecimentos sigam seu curso. Daí a recusa da Junta em transladar as oficinas de Regeneración para Morelos, a convite de Zapata. ${ }^{29}$

No entanto, esta opção deve ser vista à luz da derrota militar inicial dos liberais, uma vez que fazia parte dos planos originais da Junta transferir-se para território mexicano. Além disso, Flores Magón não alimentava ilusões acerca das possibilidades de mobilização do povo dos Estados Unidos, e logo se defrontou com a incompreensão de correligionários no próprio movimento anarquista internacional. Nesse contexto, a inflexão do seu pensamento aparece como uma resposta ideológica coerente diante dos constrangimentos apresentados pela conjuntura.

Do ponto de vista político, a mobilização da solidariedade internacional contra o intervencionismo estadunidense ganha uma importância central. A abordagem da questão por Magón é feita sob o ângulo a partir do qual ele sempre denunciou a ascendente participação econômica dos Estados Unidos no México: embora refira-se à ação dos monopólios, à cooperação entre os estados na repressão à oposição, à exploração dos trabalhadores mexicanos nos Estados Unidos e à relação deste país com a situação dos trabalhadores nacionais, Mágon nunca articulou tais problemas em uma visão estrutural dos nexos entre imperialismo e dependência. Sua denúncia da penetração do capital estadunidense esteve sempre relacionada ao risco concreto da invasão militar: "Muchos creían inofensiva la invasión del capital americano, sin sospechar que cada dólar invertido en nuestro

\footnotetext{
${ }^{29}$ A ruptura de Zapata com Madero favoreceu uma intensificação da relação com os liberais a partir de 1912: um enviado magonista de nome José Guerra sugeriu mudar o lema Justicia, Libertady Ley para Tierra y Libertad, adotado pelo exército suriano. Regeneración publicou manifestos zapatistas e os defendeu em polêmicas internacionais. Flores Magón menciona o convite a transladar-se em um artigo em 1915: "La gran fábrica de papel de San Rafael, de la que eran accionistas principales Porfirio Díaz, José Sánchez Ramos y otros “científicos”, se encuentra em poder de los zapatistas, y Emiliano Zapata ofreció a Antonio de P. Araujo poner a disposición de Regeneración todo el papel que se necesitara, em caso de que el periódico se publicase en território controlado por las fuerzas surianas". Contra el Zapatismo. Regeneración, n 209 (23/10/1915). In: BARTRA, Armando. (Prólogo, seleción y notas). Regeneración, 1900-1918. La corriente más radical de la revolución mexicana de 1910 a 1918 através de su peródico de combate. Cidade do México: Era, 1977,p. 360.
} 
país está apoyado por una bayoneta sajona pronta a derramar sangre mexicana al primer síntoma de peligro". ${ }^{30}$

A internacionalização do enfoque revolucionário, que corresponde à radicalização anticapitalista do discurso magonista, provoca o recrudescimento da perseguição política das autoridades dos Estados Unidos. Além do crescente envolvimento deste país com o conflito mexicano, a convergência da propaganda liberal com o radicalismo dos trabalhadores nacionais leva o governo dos Estados Unidos a assumir a perseguição liberal por conta própria. Como resultado, Flores Magón é preso duas vezes em 1911 por períodos curtos, e no ano seguinte é condenado por violação das leis de neutralidade em função do episódio da Baja California, ficando encarcerado até janeiro de 1914.

Neste meio tempo o comandante liberal Jesús Maria Rangel, preso pelas tropas maderistas em 1911, obteve a liberdade com a derrubada de Madero em fevereiro de 1913. Logo depois de entrevistar-se com Zapata, com o objetivo de coordenar esforços militares, rumou ao Texas onde organizou uma pequena milícia que foi surpreendida por forças dos Estados Unidos antes de atravessar a fronteira. Os liberais capturados foram sentenciados a altíssimas penas, o que gerou uma vigorosa, embora infrutífera, campanha em favor da libertação dos "mártires do Texas". Foi a última tentativa de uma iniciativa militar explicitamente sob a bandeira liberal. Embora em junho de 1914, novamente em liberdade, Flores Magón tenha enumerado um conjunto de forças liberais em batalha, é difícil saber a quem elas realmente obedeciam, sendo improvável que fossem fiéis a qualquer comando unificado. ${ }^{31}$

Ainda que o poder de mobilização magonista decline definitivamente a partir de 1914, o acirramento da perseguição aos movimentos de esquerda nos Estados

\footnotetext{
${ }^{30}$ FLORES MAGÓN, Ricardo. Obras Completas - Vol. I. Correspondencia (1898-1918). BARRERA BASSOLS, Jacinto. (Introducción, compilación y notas). Cidade do México: Conaculta, 2001, p. 339.

31 Torres Parés descreve os esforços conduzidos por Jesús Rangel. Em seguida pondera: "El balance de la situación de las fuerzas liberales realizado por Ricardo Flores Magón en junio de 1914 no necesariamente representa um recuento exacto de su capacidad militar. Es en realidad uma valoración de carácter político (...)" TORRES PARÉS. La Revolución sin frontera. Cidade do México: UNAM, 1990, p. 185. Em outro lugar, este autor sugere: “(...) pertinente abordar la crítica del pensamiento magonista desde la perspectiva de su función política, es decir, entendida como un "fermento", como una "incitación a la acción", y no solo desde el punto de vista de la precisión de sus datos". Embora seja evidente que o pensamento magonista obedeça ao imperativo da ação política, a sua evolução segue uma coerência interna lastreada em uma visão de mundo própria e na avaliação da conjuntura, que deve ser explicitada para que se proceda à crítica, sem necessidade de recorrer a uma explicação apoiada em Georges Sorel (1847-1922), como sugere Torres Parés.
} 
Unidos diante da Grande Guerra e da revolução bolchevique atingiu os líderes liberais. ${ }^{32}$ Magón é preso novamente em fevereiro de 1916 por seis meses, junto com seu irmão Enrique. Em 1918, é condenado por violação às leis de espionagem em função de um manifesto que assinara, o que lhe impõe uma sentença de 20 anos de prisão e multa de U\$ 5000. Com 45 anos, a saúde comprometida por múltiplas complicações que certamente se agravariam no cárcere, quase cego, o líder liberal interpretou corretamente esta sentença como uma prisão perpétua.

Morreu em novembro de 1921, provavelmente assassinado na prisão. Seu corpo foi imediatamente solicitado pelo congresso mexicano, ineficaz até então para pressionar pela sua libertação em vida, ${ }^{33} \mathrm{e}$ trazido para o país por intermédio dos trabalhadores ferroviários. Sua figura começava a ser reivindicada ideologicamente pelo Estado, em uma operação de incorporação e neutralização ideológica dos adeptos irredutíveis da causa popular na Revolução Mexicana derrotada. ${ }^{34}$

\section{Balanço político e ideológico}

A implacável perseguição engendrada pela ditadura contra os liberais mexicanos, no país e no exílio, limitou o êxito de suas tentativas de liderar a revolta anti-porfirista. Quando a luta armada afinal desencadeou-se, logo ficou evidente a incompatibilidade entre o conteúdo democrático da revolução defendida pelos liberais e a luta política empreendida pelo maderismo. Uma vez derrubada a ditadura, as forças triunfantes voltaram-se para a contenção dos setores populares, segundo um padrão que prevaleceria ao longo do processo. As sucessivas derrotas das tentativas de conter a pressão popular revolucionária são testemunho da formidável energia política mobilizada, ao mesmo tempo que explicitam a rigidez dos constrangimentos sob os quais operava a classe dominante, dividida e incapaz de integrar as demandas sociais como caminho para a paz nacional. Diante desta disjuntiva, o magonismo radicalizou suas consignas, explicitando uma permeabi-

\footnotetext{
${ }^{32}$ O refluxo do ímpeto popular da revolução não arrefeceu o otimismo dos artigos em Regeneración, compensado por uma crescente esperança na radicalização da conjuntura mundial. Neste período, Magón reforça a orientação pedagógica dos seus escritos: publica curtas parábolas destinadas aos trabalhadores e elabora duas peças de teatro.

${ }^{33}$ Enquanto esteve preso, declinou oferta do governo dos Estados Unidos para ser libertado mediante uma confissão de arrependimento, ao mesmo tempo em que viu a justiça negar sistematicamente qualquer atenuante à sua condição carcerária, apesar da piora dramática do seu estado de saúde. Recusou também uma pensão vitalícia oferecida pelo governo mexicano recém-egresso da revolução.

${ }^{34}$ Magón foi sepultado no Panteon Francés (cemitério no sul da capital). Em 1937 o governo Cárdenas, principal responsável pela reivindicação de Pancho Villa, iniciou gestão para trasladar seus restos mortais para a Rotonda de los Hombres Ilustres, no Panteón de Dolores.
} 
lidade ideológica que permitiu novas respostas teóricas ao movimento da conjuntura, de modo a revelar-se, ao mesmo tempo, como virtude e debilidade política.

A resposta magonista à prova revolucionária revelou uma fina sensibilidade para a dinâmica da luta de classes no México. Na medida em que se evidenciou a intransigência social das classes dominantes e o potencial subversivo da luta no campo, Flores Magón assumiu o desafio de fundamentar a revolução anticapitalista em um país agrário. Sua argumentação segue um duplo movimento: por um lado, valoriza a tendência anti-autoritária, que interpreta como instintiva aos homens; por outro lado, reivindica o legado das instituições indígenas para a formação mexicana, identificando-as com um passado comunista de potencial progressista.

A consequência deste movimento teórico é um rebaixamento do imperativo da direção política em nome de uma valorização da iniciativa instintiva das massas, em oposição à racionalidade política anteriormente afirmada por Flores Magón. Nessa perspectiva, a função da minoria consciente se dilui diante do espetáculo irresistível do fluxo da ação humana liberado. Uma vez removidos os impedimentos históricos de caráter autoritário, a natureza humana, boa e solidária, se imporá. ${ }^{35}$

$\mathrm{Na}$ raiz do esvaziamento das mediações entre natureza e história está uma correspondência entre instinto e liberdade, plena de consequências políticas: a noção de que a remoção dos entraves históricos conduz ao fluxo da natureza humana implica na prescindência de qualquer modalidade de centralização do poder, interpretada como contraditória ao caráter natural, instintivo e solidário da liberdade. Daí a ausência de uma teoria da transição, do Estado, e de um trabalho de direção revolucionária. ${ }^{36}$

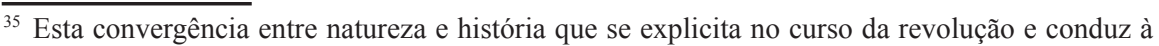
subordinação do movimento à ação, aponta para uma influência positivista na visão de mundo magonista, no sentido de uma tendência a naturalizar as dinâmicas sociais e os processos da história em oposição a uma abordagem dialética destes fenômenos. A marca do positivismo em sua formação é enfatizada por Blanquel: "Flores Magón se formó pues en el positivismo, es decir, en el cuerpo de ideas que adaptadas a la realidad mexicana, fuero en soporte de la cultura y también, en buena parte, del quehacer social y político del México porfiriano". BLANQUEL, Eduardo. Ricardo Flores Magón. Cidade do México: Editorial Terra Nova, 1985, p. 23. Evidentemente, Flores Magón não comunga do sentido político do pensamento positivo, situando-se nas antípodas de qualquer apologia da ordem. Sobre a oposição entre positivismo e dialética ver: MARCUSE, Herbert. Razão e Revolução. Rio de Janeio: Paz e Terra, 2a edição, 1978, p. 302.

36 "Sin embargo, la problemática del pensamiento anarquista se hace patente cuando se analiza la conceptualización del tránsito desde la realidad sojuzgada del presente al futuro de libertad. Como este futuro es un futuro de relaciones sociales sin ninguna institucionalización y sin autoridad, el anarquista no puede pensar el tránsito al futuro en términos mediatizados; entre el presente
} 
Como resultado, à medida que o Partido Liberal é derrotado militarmente, ao tempo em que a revolução camponesa experimenta um ascenso fulminante, em lugar de requalificar os desafios da vanguarda revolucionária, Flores Magón interpreta positivamente as possibilidades da ação espontânea. Paradoxalmente, no momento em que a revolução ascende, o partido tem debilitadas suas possibilidades organizativas. Isso se deve primordialmente à derrota militar, mas é reforçado pela avaliação de que a revolução deve prescindir de chefes, o que, em nome da superestimação dos impulsos revolucionários, encolhe o terreno da ação política dirigida. Em uma palavra, a política cede terreno para a natureza.

Do ponto de vista do pensamento histórico, este encolhimento da política tem por consequência um acento na inexorabilidade da revolução mundial. Ao enfatizar os vínculos do processo mexicano com o movimento da história universal, que estaria destinado a superar o capitalismo, seu enfoque da revolução passa a ter uma angulação mundial, assentado em uma teleologia antes ausente, quando seus artigos estavam rigorosamente enquadrados pelo dinamismo da conjuntura mexicana imediata. Ao estreitamento do pensamento político corresponde um alargamento da teleologia histórica.

Em suma, quando a revolução é detonada, observa-se um encolhimento do espaço e da necessidade de atuação política em nome de uma prevalência das determinações da natureza: o instinto e a teleologia entram no lugar da vanguarda e do partido. A consequência programática é a ausência de um projeto nacional mediado pelo Estado e a aposta no enfrentamento direto e localizado da propriedade privada: o horizonte magonista é o de uma federação supranacional de produtores solidários. Seu projeto conjuga diretamente o local, que remete ao passado das tradições comunais indígenas, com as tendências anticapitalistas do proletariado mundial: "Flores Magón, sin abandonar el siglo XIX, se incorporo de lleno en el siglo $X X$ ". 37

Ao abandonar o projeto nacional em nome de uma naturalização do curso da história - ancorado em uma valorização dos instintos populares desencadeados pela revolução, minimizando a importância das tarefas organizativas e de

y el futuro hay un abismo sin ningún puente institucional". HINKELAMMERT, Franz. Crítica de la razón utópica. Edição virtual disponível no sítio: www.pensamientocritico.info.libros. De outro lado, o maderismo e os exércitos sucessivos que combateram reivindicando o seu legado não sofreram essa limitação, balizando a sua ação pelo mínimo denominador comum entre a reforma política e a contenção da rebeldia popular, o que lhes permitiu concessões demagógicas e alianças espúrias funcionais em nome de um projeto de poder. A liderança de tipo caudilhesco se mostrou eficaz para gerar coesão política e motivar a adesão popular.

${ }^{37}$ TORRES PARÉS, Javier. La Revolución sin frontera. Cidade do México: UNAM, 1990, p. 173. 
direção -, os magonistas inadvertidamente reforçaram a principal debilidade do campo popular na revolução: sua incapacidade de superar o regionalismo em nome de um projeto de nação, em meio a uma guerra camponesa prolongada. ${ }^{38}$

Esta carência se evidenciou de forma dramática em dezembro de 1914 quando o chamado Exército Constitucionalista, liderado por Venustiano Carranza, estava acuado em Veracruz e o movimento popular atingiu seu ápice, emblematicamente registrado na fotografia de Pancho Villa sentado ao lado de Emiliano Zapata na cadeira presidencial. O triunfo momentâneo em armas, no entanto, não se traduziu na consumação da reivindicação dos de baixo. Na raiz desse fracasso encontram-se a impossibilidade dos zapatistas de avançarem para além das comunas agrárias de Morelos, bem como a incapacidade de Villa de superar uma visão regionalista, marcada pelo ódio às oligarquias, a resistência à centralização e o desprezo pela democracia. Apesar das limitações militares que derrotariam a División Del Norte no ano seguinte, do ponto de vista político, as forças villistas e zapatistas se revelaram incapazes de articular uma alternativa sólida de poder nacional, e o governo estabelecido a partir da convenção de Aguascalientes rapidamente naufragou. A ausência no plano ideológico de um projeto nacional definido correspondeu, em termos políticos, à incapacidade de constituir uma alternativa de poder autônoma e viável de alcance nacional. ${ }^{39}$

O magonismo foi incapaz política e ideologicamente de contribuir para superar esta lacuna. Por outro lado, a falta de rigidez teórica de um pensamento que advogava a primazia da ação favoreceu uma sensibilidade avessa a todo dogmatismo e atenta aos movimentos da conjuntura. Isto possibilitou a Flores Magón manter à frente de Regeneración uma crítica vigorosa e lúcida tanto antes quanto durante o processo revolucionário, denunciando as manobras contra-revolucionárias até a extinção final do periódico em 1918. Esta sensibilidade

\footnotetext{
${ }^{38}$ Na visão de Bartra, neste contexto o desafio enfrentado pelo PLM a partir de 1911 seria "organizar y dirigir el campesinato, no como um partido distinto sino como la fuerza mayoritaria del propio partido proletário... Ante una revolución que no podía resolverse más que como una guerra popular y prolongada en el campo, la única alternativa viable era del tipo de la que implantó, muchos años después, el Partido Comunista Chino". BARTRA, Armando. La revolución mexicana de 1910 en la perspectiva del magonismo. In: GILLY, Adolfo (Org.). Interpretaciones de la Revolución Mexicana. Cidade do México: UNAM, Editorial Nueva Imagen, 1980, p. 107.

${ }^{39} \mathrm{O}$ "Programa de reformas político-sociales de la revolución aprobado por la soberana convención revolucionaria" divulgado pelos zapatistas desde Morelos em 18 de abril de 1916 é um notável esforço para responder a este desafio em um momento em que o campo popular já perdera a iniciativa revolucionária. In: DÍAZ, Lilia (selección y traducción). Planes políticos y otros documentos. Fuentes para la historia de la Revolución Mexicana. Prólogo de Manuel González Ramirez. Cidade do México: FCE, 1954, p. 123-8.
} 
permitiu ao líder liberal reconhecer o protagonismo camponês no processo, apoiá-lo entusiasticamente e ser com ele derrotado.

\section{Referências bibliográficas}

\section{Fontes}

DÍAZ, Lilia (selección y traducción). Planes políticos y otros documentos. Fuentes para la historia de la Revolución Mexicana. Prólogo de Manuel González Ramirez. Cidade do México: FCE, 1954.

FLORES MAGÓN, Ricardo. Obras Completas - Vol. I. Correspondencia (18981918). Introducción, compilación y notas, Jacinto Barrera Bassols. Cidade do México: Conaculta, 2000.

Vol. II. Correspondencia 2 (1919-1922). Introducción, compilación y notas, Jacinto Barrera Bassols. Cidade do México: Conaculta, 2000.

Vol. III. Regeneración (1900-1901) Primera parte. Introducción, compilación y notas, Jacinto Barrera Bassols. Cidade do México: Conaculta, 2003.

Vol. IV. Regeneración (1900-1901) Segunda parte. Introducción, compilación y notas, Jacinto Barrera Bassols. Cidade do México: Conaculta, 2003.

. Vol. V. Artículos Políticos Seudónimos. Introducción, compilación y notas, Jacinto Barrera Bassols. Cidade do México: Conaculta, 2005.

. Versión digital completa del periódico Regeneración. Preparada por Jacinto Barrera Bassols, Cidade do México: INAH.

REGENERACIÓN. Regeneración, 1900-1918. La corriente más radical de la revolución mexicana de 1910 a 1918 através de su peródico de combate. Prólogo, seleción y notas de Armando Bartra. Cidade do México: Era, 1977.

\section{Bibliografia}

ABAD DE SANTILLÁN, Diego. Ricardo Flores Magón. El Apóstol de la Revolución Social Mexicana. Cidade do México: CEHSMO, 1978.

AGUILAR CAMÍN, Héctor. La frontera nómada: Sonora y la revolución mexicana. $3^{\text {a }}$ edición. Cidade do México: Siglo XXI, 1981.

AGUIRRE BELTRÁN, Gonzalo. Ricardo Flores Magón. In: Idem, Obra Antropológica XV. Crítica Antropológica. Contribuiciones al estudio del pensamiento social en México. Cidade do México: FCE, 1990.

ALBRO, Ward S. Always a rebel. Ricardo Flores Magón and the Mexican Revolution. Fort Worth: Texas Christian University Press, 1992.

AZAOLA GARRIDO, Elena. Rebelión y derrota del magonismo agrario. Cidade do México: SEP; FCE, 1982. 
BARTRA, Armando. La revolución mexicana de 1910 en la perspectiva del magonismo. In: GILLY, Adolfo (Org.). Interpretaciones de la Revolución Mexicana. Cidade do México: UNAM, Editorial Nueva Imagen, 1980.

BETHELL, Leslie (Ed.). Mexico since independence. Cambridge: Cambridge University Press, 1991.

BLANQUEL, Eduardo. Ricardo Flores Magón. Cidade do México: Editorial Terra Nova, 1985.

CARR, Barry. El movimiento obrero y la política en México. 1910/1929. Cidade do México: Era, 1981.

COCKROFT, James D. Precursores intelectuales de la Revolución Mexicana (19001913). Traducción de María Eunice Barrales. Cidade do México: Siglo XXI, 1985.

COLE, G. D. H. Historia del pensamiento socialista. vol. IV. La segunda internacional (1889-1814), primera parte. Traducción de Enrique González Pedrero. Cidade do México: FCE, 1974. 1974.

. vol II. Marxismo y anarquismo (1850-1890). Cidade do México: FCE,

CÓRDOVA, Arnaldo. La ideología de la Revolución Mexicana. La formación del nuevo regimen. 23ª reimpressão. Cidade do México: Era, 1973.

COSÍO VILLEGAS, Daniel. (coord.). Historia General de México. 2 tomos. Cidade do México: El Colegio de Mexico, 1976.

CRAGNOLINO, Silvia. La huelga de Cananea. Historia del Movimiento obrero, 29, Buenos Aires: Centro Editor de America Latina, 1973.

CUAUHTÉMOC ESPARZA VALDIVIA, Ricardo. El fenómeno magonista en México y Estados Unidos, 1905-1908. Zacatecas: Universidad Autónoma de Zacatecas, 2000.

DELFÍN GUILLAUM, Martha. La toma de Tijuana en 1911. Flores Magón y la revolución anarquista. Revista Veredas, vol. 4, n. 7, 2003, p. 167-173.

GARCÍA CANTU, Gastón. El socialismo en México, siglo XIX. Cidade do México: Era, 1969.

GILLY, Adolfo (Org.). Interpretaciones de la Revolución Mexicana. Cidade do México: UNAM, Editorial Nueva Imagen, 1980.

La revolución interrumpida. Cidade do México: Ediciones El Caballito, sem data.

HART, John M. Anarchism and the Mexican Working Class. (1860-1931). Austin: University of Texas Press, 1978.

HERNANDEZ PADILLA, Salvador. El Magonismo: historia de una pasión libertaria. 1900-1922. Cidade do México: Era, 1996.

. Itinerarios del magonismo en la Revolución Mexicana. Contrahistorias

- la otra mirada de Clio, n. 4, 2005, p. 21-38. 
HINKELLMMERT, Franz. Crítica de la razón utópica. Edição virtual disponível no sítio: www.pensamientocritico.info.libros.

KATZ, Friederich (compilador). Revuelta, rebelión y revolución. La lucha rural en México del siglo XVI al siglo XX. 2 tomos. Cidade do México: Era, 1990.

. The life and times of Pancho Villa. Palo Alto: Stanford University Press, 1998.

. La Guerra Secreta en México. $6^{\mathrm{a}}$ reimpressión. Cidade do México: Era, 1982.

(copilación y introducción). La servidumbre agraria en México en la época porfiriana. Cidade do México: Era, 2002.

KNIGHT, Alan. The Mexican Revolution. 2 volumes. Lincoln: University of Nebraska Press, 1990.

Interpretaciones recientes de la Revolución Mexicana. Revista Secuencia, Cidade do México, Instituto de Investigaciones Dr. José María Luis Mora, n. 13, ene.-abr. 1989, p. 23-43.

LÓPEZ CAMARA, Francisco. La estructura económica y social de México. Cidade do México: Siglo XXI, 8 a edición, 1982.

MACLACHLAN, Colin M. Anarchism and the Mexican Revolution - the political trials of Ricardo Flores Magón in the United States. Berkeley: University of California Press, 1991.

MARCUSE, Herbert. Razão e Revolução. Rio de Janeiro: Paz e Terra, $2^{\mathrm{a}}$ edição, 1978.

MOLINA ENRIQUEZ, Andres. Los grandes problemas nacionales. Cidade do México: INJM, 1964.

OCHOAAVILA, Enrique. El pensamiento de Ricardo Flores Magón: su concepción antropológica. Cuadernos Americanos, Cidade do México, vol. 5, n. 101, 2003, p. 59-71.

PEÑA, Sergio de la. La formación del capitalismo en México. Cidade do México: Siglo XXI, 1975.

RAAT, W. Dirk. Los revoltosos. Rebeldes mexicanos en los Estados Unidos (19031923). Cidade do México: FCE, 1993.

RABASA, Emilio. La constitución y la dictadura. Primera edición de Cien de México. Cidade do México: Conaculta, 2002.

REED, John. México Insurgente. Traducción de: Ignacio de Llorens. Cidade do México: Editores Mexicanos Unidos, 2003.

REYES HEROLES, Jesús. El liberalismo mexicano. 3 tomos. Cidade do México: FCE.

SEMO, Enrique. Historia Mexicana - economía y lucha de clases. Cidade do México: Era, 1985.

SIERRA, Justo. Evolución Política del Pueblo Mexicano. Cidade do México: SEP; UNAM, 1981. 
SILVA HERZOG, Jesus. Breve Historia de la Revolución Mexicana. 2 tomos. $15^{\mathrm{a}}$ reimpressión. Cidade do México: FCE, 1995.

. Trayectoria ideológica de la Revolución Mexicana y otros ensayos. Cidade do México: FCE, 1994.

TAYLOR, Lawrence Douglas. La campaña magonista de 1911 en Baja California. Tijuana: El Colegio de la Frontera Norte, 1992.

TORRE, Alejandro de la. Las agrupaciones políticas consignadas en Regeneración, 1900-1918. Distribución geográfica de una extensa red de solidaridades políticas. In: BARRERA BASSOLS, Jacinto (org.). Regeneración. Edição digital completa em CD Rom.

TORRES PARÉS, Javier. La Revolución sin frontera. Cidade do México: UNAM, 1990.

TURNER, Ethel Duffy. Ricardo Flores Magón y el Partido Liberal Mexicano. Sem menção do tradutor. Cidade do México: Comisión Editorial Nacional, 1984.

TURNER, John Keneth. México Bárbaro. Sem menção do tradutor. Cidade do México: Costa-amic editor, sem data.

URIOSTEGUI MIRANDA, Pindaro. Testimonio del proceso revolucionario de México. Cidade do México: Argrin, 1970.

WOMACK JR, John. Zapata and the Mexican Revolution. Nova Iorque: Vintage Books, 1970.

ZEA, Leopoldo. El positivismo en Mexico: nacimiento, apogeo y decadencia. $7^{\mathrm{a}}$ reimpresión. Cidade do México: FCE, 1993.

Recebido: 05/04/2010 - Aprovado: 02/09/2011 